\title{
Analysing surface energy balance closure and partitioning over a semi-arid savanna FLUXNET site in Skukuza, Kruger National Park, South Africa
}

\author{
Nobuhle P. Majozi ${ }^{1,2}$, Chris M. Mannaerts ${ }^{2}$, Abel Ramoelo ${ }^{1,5}$, Renaud Mathieu ${ }^{1,3}$, Alecia Nickless ${ }^{4}$, and \\ Wouter Verhoef ${ }^{2}$ \\ ${ }^{1}$ Earth Observation Group, Natural Resources and Environment, Council for Scientific and Industrial Research, \\ Pretoria, 0001, South Africa \\ ${ }^{2}$ Department of Water Resources, Faculty of Geo-Information Science and Earth Observation (ITC), \\ University of Twente, Enschede, 75AA, the Netherlands \\ ${ }^{3}$ Department of Geography, Geoinformatics and Meteorology, University of Pretoria, Pretoria, South Africa \\ ${ }^{4}$ Nuffield Department of Primary Care Health Sciences, University of Oxford, Oxford, OX2 6GG, UK \\ ${ }^{5}$ University of Limpopo, Risk and Vulnerability Centre, Sovenga, 0727, South Africa
}

Correspondence to: Nobuhle P. Majozi (nmajozi@csir.co.za)

Received: 23 December 2016 - Discussion started: 16 January 2017

Revised: 11 April 2017 - Accepted: 30 May 2017 - Published: 10 July 2017

\begin{abstract}
Flux towers provide essential terrestrial climate, water, and radiation budget information needed for environmental monitoring and evaluation of climate change impacts on ecosystems and society in general. They are also intended for calibration and validation of satellite-based Earth observation and monitoring efforts, such as assessment of evapotranspiration from land and vegetation surfaces using surface energy balance approaches.

In this paper, 15 years of Skukuza eddy covariance data, i.e. from 2000 to 2014, were analysed for surface energy balance closure (EBC) and partitioning. The surface energy balance closure was evaluated using the ordinary least squares regression (OLS) of turbulent energy fluxes (sensible $(\mathrm{H})$ and latent heat (LE)) against available energy (net radiation $(\mathrm{Rn})$ less soil heat $(\mathrm{G})$ ), and the energy balance ratio (EBR). Partitioning of the surface energy during the wet and dry seasons was also investigated, as well as how it is affected by atmospheric vapour pressure deficit (VPD), and net radiation.

After filtering years with low-quality data (2004-2008), our results show an overall mean EBR of 0.93. Seasonal variations of EBR also showed the wet season with 1.17 and spring (1.02) being closest to unity, with the dry season (0.70) having the highest imbalance. Nocturnal surface energy closure was very low at 0.26 , and this was linked to
\end{abstract}

low friction velocity during night-time, with results showing an increase in closure with increase in friction velocity.

The energy partition analysis showed that sensible heat flux is the dominant portion of net radiation, especially between March and October, followed by latent heat flux, and lastly the soil heat flux, and during the wet season where latent heat flux dominated sensible heat flux. An increase in net radiation was characterized by an increase in both $\mathrm{LE}$ and $\mathrm{H}$, with LE showing a higher rate of increase than $\mathrm{H}$ in the wet season, and the reverse happening during the dry season. An increase in VPD is correlated with a decrease in LE and increase in $\mathrm{H}$ during the wet season, and an increase in both fluxes during the dry season.

\section{Introduction}

Net solar radiation $(\mathrm{Rn})$ reaching the Earth's surface determines the amount of energy available for latent (LE), sensible $(\mathrm{H})$, and soil $(\mathrm{G})$ heat fluxes, and heat stored by the canopy, the ground, and energy storage terms by photosynthesis. Energy partitioning on the Earth's surface is a function of interactions between biogeochemical cycling, plant physiology, the state of the atmospheric boundary layer, and 
climate (Wilson et al., 2002). How the turbulent fluxes (H and LE) are partitioned in an ecosystem plays a critical role in determining the hydrological cycle, boundary layer development, weather, and climate (Falge et al., 2005). Understanding the partitioning of energy, particularly the turbulent fluxes, is important for water resource management in (semi) arid regions, where reference evapotranspiration far exceeds precipitation.

Eddy covariance (EC) systems are currently the most reliable method for measuring carbon, energy, and water fluxes, and they have become a standard technique in the study of surface-atmosphere boundary layer interactions. They provide a distinct contribution to the study of environmental, biological and climatological controls of the net surface exchanges between the land surface (including vegetation) and the atmosphere (Aubinet, et al., 1999; Baldocchi et al., 2001). The accuracy of these data is very important because they are used to validate and assess performance of land surface and climate models. However, the EC techniques have limitations in terms of data processing and quality control methods, especially under complex conditions (e.g. unfavourable weather, such as high turbulence and low wind speed, and heterogeneous topography). In EC measurements, the ideal situation is that available energy, i.e. net radiation minus soil heat flux, is equal to the sum of the turbulent fluxes $(\mathrm{Rn}-\mathrm{G}=\mathrm{LE}+\mathrm{H})$; however, in most instances, the measured available energy is larger than the sum of the measured turbulent fluxes of sensible heat and latent heat. Extensive research on the issue of surface energy imbalance in EC observations has been done (Barr et al., 2012; Chen et al., 2009; Foken et al., 2010; Franssen et al., 2010; Mauder et al., 2007), and closure error (or imbalance) has been documented to be around 10-30\% (Wilson et al., 2002; von Randow et al., 2004; Sánchez et al., 2010).

Causes for non-closure, as extensively discussed, include unaccounted soil and canopy heat storage terms, noninclusion of the low- and high-frequency turbulence in the computation of the turbulent fluxes, land surface heterogeneities, systematic measurement and sampling errors. This imbalance has implications on how energy flux measurements should be interpreted and how these estimates should be compared with model simulations. The surface energy balance closure is an accepted performance criterion of EC flux data (Twine et al., 2000; Wilson et al., 2002), and different methods have been used to assess the energy closure and partitioning, including ordinary least squares regression (OLS) method, i.e. a plot of turbulence fluxes $(\mathrm{H}+\mathrm{LE})$ against available energy $(\mathrm{Rn}-\mathrm{G})$, the residual method, i.e. $\mathrm{Rn}-\mathrm{G}-\mathrm{H}-\mathrm{LE}$, and the energy balance ratio, i.e. $(\mathrm{H}+\mathrm{LE}) /(\mathrm{Rn}-\mathrm{G})$.

Several researchers have investigated surface energy partitioning and energy balance closure for different ecosystems, including savannas. Bagayoko et al. (2007) examined the seasonal variation of the energy balance in West African savannas, and noted that latent heat flux played a major role in the wet season, whereas sensible heat flux was significant in the dry season. In the grassland Mongolian Plateau, $\mathrm{Li}$ et al. (2006) concluded that sensible heat flux dominated the energy partitioning, followed by ground heat flux, with the rainy season showing slight increase in latent heat flux. $\mathrm{Gu}$ et al. (2006) used different ratios (Bowen ratio, G / Rn, $\mathrm{H} / \mathrm{Rn}$ and LE / Rn) to investigate surface energy exchange in the Tibetan Plateau, and showed that during the vegetation growth period, LE was higher than $\mathrm{H}$, and this was reversed during the post-growth period.

Research using the Skukuza EC system data has focused mainly on the carbon exchange, fire regimes, and in global analysis of the energy balance (Archibald et al., 2009; Kutsch et al., 2008; Williams et al., 2009). However, there has been no investigation of surface energy partitioning and energy balance closure in this ecosystem. In this study, we examined the surface energy balance partitioning into soil heat conduction, convection (sensible), and latent heat components and its energy balance closure using 15 years (2000-2014) of eddy covariance data from the Skukuza flux tower.

First, a multi-year surface energy balance closure (EBC) analysis was done, including the seasonal and day-night EBC evaluations, role of G on EBC, and an assessment of its error sources. This included investigating how friction velocity affects the closure, and its link to low night-time EBC. Then, we examined how the surface energy partitioning varies with time in this ecosystem, based on the weather conditions in the region, particularly, in relation to water availability (precipitation) and vegetation dynamics. The effect of vapour pressure deficit (VPD) and Rn on the energy partitioning between turbulent fluxes during the wet and dry seasons was also examined. Through this study, we expect to contribute to existing literature on the surface energy balance closure and partitioning, especially in semi-arid savanna areas.

\section{Materials and methods}

\subsection{Site description}

The Skukuza flux tower $\left(25.02^{\circ} \mathrm{S}, 31.50^{\circ} \mathrm{E}\right)$ was established in early 2000 as part of the SAFARI 2000 campaign and experiment, set up to understand the interactions between the atmosphere and the land surface in Southern Africa by connecting ground data of carbon, water, and energy fluxes with remote sensing data generated by Earth-observing satellites (Scholes et al., 2001; Shugart et al., 2004).

The site is located in the Kruger National Park (South Africa) at $365 \mathrm{~m}$ above sea level, and receives $550 \pm 160 \mathrm{~mm}$ precipitation per annum between November and April, with significant inter-annual variability. The year is divided into a hot, wet growing season and a warm, dry non-growing season. The soils are generally shallow, with coarse sandy to sandy loam textures (about $65 \%$ sand, $30 \%$ clay and $5 \%$ silt). The area is characterized by a catenal pattern of soils 
Table 1. Measurements taken and instruments used at Skukuza flux tower.

\begin{tabular}{|c|c|c|}
\hline Instrument & Model/brand & Measurement \\
\hline Sonic anemometer & $\begin{array}{l}\text { Gill Instruments Solent R3, Hampshire, } \\
\text { England }\end{array}$ & $\begin{array}{l}\text { Three-dimensional, orthogonal compo- } \\
\text { nents of velocity }\left(u, v, w\left(\mathrm{~m} \mathrm{~s}^{-1}\right)\right) \text {, } \\
\text { sonic temperature }\end{array}$ \\
\hline Closed path gas analyser & IRGA, LI-COR 6262, LI-COR, Lincoln & $\begin{array}{l}\text { Water vapour, carbon dioxide concen- } \\
\text { trations }\end{array}$ \\
\hline Radiometer & $\begin{array}{l}\text { Kipp \& Zonen CNR1, Delft, the } \\
\text { Netherlands }\end{array}$ & $\begin{array}{l}\text { Incoming and outgoing longwave and } \\
\text { shortwave radiation }\end{array}$ \\
\hline HFT3 plates & Campbell Scientific & $\begin{array}{l}\text { Soil heat flux at } 5 \mathrm{~cm} \text { depth with three } \\
\text { replicates, i.e. two under tree canopies } \\
\text { and one on open space }\end{array}$ \\
\hline Frequency domain reflectometry probes & $\begin{array}{l}\text { Campbell Scientific CS615, Logan, } \\
\text { Utah }\end{array}$ & $\begin{array}{l}\text { Volumetric soil moisture content with } \\
\text { two in the Acacia-dominated soils } \\
\text { downhill of the tower at } 3,7,16 \text {, } \\
30 \text {, and } 50 \mathrm{~cm} \text {, and another two at } 5 \text {, } \\
13,29 \text {, and } 61 \mathrm{~cm} \text { in the Combretum- } \\
\text { dominated soils uphill }\end{array}$ \\
\hline
\end{tabular}

and vegetation, with broad-leaved Combretum savanna on the crests dominated by the small trees (Combretum apiculatum), and fine-leaved Acacia savanna in the valleys dominated by Acacia nigrescens (Scholes et al., 1999). The vegetation is mainly open woodland, with approximately $30 \%$ tree canopy cover of mixed Acacia and Combretum savanna types. Tree canopy height is $5-8 \mathrm{~m}$ with occasional trees (mostly Sclerocarya birrea) reaching $10 \mathrm{~m}$. The grassy and herbaceous understorey comprises grasses such as Panicum maximum, Digitaria eriantha, Eragrostis rigidor, and Pogonarthria squarrosa.

\subsubsection{Eddy covariance system}

Since 2000, ecosystem-level fluxes of water, heat, and carbon dioxide have been measured using an eddy covariance system mounted at $16 \mathrm{~m}$ height of the $22 \mathrm{~m}$ high flux tower. The measurements taken and the instruments used are summarized in Table 1.

From 2000 to 2005, $\mathrm{H}$ and LE were derived from a closedpath $\mathrm{CO}_{2} / \mathrm{H}_{2} \mathrm{O}$ monitoring system, which was replaced by the open-path gas analyser in 2006. Also, from 2000 to 2008, incident and reflected shortwave radiation (i.e. 300$1100 \mathrm{~nm}, \mathrm{~W} \mathrm{~m}^{-2}$ ), incident and reflected near-infrared (600$1100 \mathrm{~nm}, \mathrm{~W} \mathrm{~m}^{-2}$ ) and incoming and emitted longwave radiation $\left(>3.0 \mu \mathrm{m}, \mathrm{W} \mathrm{m}^{-2}\right)$ measurements were made using a two-component net radiometer (model CNR 2: Kipp $\&$ Zonen, Delft, the Netherlands) at $20 \mathrm{~s}$ intervals and then recorded in the data logger as $30 \mathrm{~min}$ averages; this was replaced with the Kipp \& Zonen NR-Lite net radiometer in 2009. Soil heat flux is measured using the HFT3 plates (Campbell Scientific) installed at $5 \mathrm{~cm}$ below the surface at three locations - two under tree canopies and one between canopies.

Ancillary meteorological measurements include air temperature and relative humidity, also measured at $16 \mathrm{~m}$ height, using a Campbell Scientific HMP50 probe; precipitation at the top of the tower using a Texas TR525M tipping bucket rain gauge; wind speed and direction using a Climatronics wind sensor; and soil temperature using Campbell Scientific 107 soil temperature probe.

\subsubsection{Data pre-processing}

The Eddysoft software was used to process the raw data collected from the eddy covariance system (Kolle and Rebmann, 2007). Post-processing of the raw high-frequency $(10 \mathrm{~Hz})$ data for calculation of half-hour periods of the turbulent fluxes and $\mathrm{CO}_{2}\left(F_{\mathrm{c}} ; \mathrm{g} \mathrm{CO}_{2} \mathrm{~m}^{-2}\right.$ time $\left.{ }^{-1}\right)$ involved standard spike filtering, planar rotation of velocities, and lag correction to $\mathrm{CO}_{2}$ and $q$ (Aubinet et al., 1999; Wilczak et al., 2001). Frequency response correction of some of the energy lost due to instrument separation, tube attenuation, and gas analyser response for LE and $F_{\mathrm{c}}$ was performed with empirical cospectral adjustment to match the $\mathrm{H}$ co-spectrum (Eugster and Senn, 1995; Su et al., 2004).

\subsection{Data analysis}

Half-hourly measurements of eddy covariance and climatological data from 2000 to 2014 were used to assess surface energy partitioning and closure. When measuring the different variables, instruments like the sonic anemometer and the net radiometer are affected by different phenomena, like rainfall events and wind gusts, resulting in faulty diagnostic sig- 
nals, outliers and data gaps, which are sources of error and bias. Thus, cleaning, which involved screening, diagnosing and editing, of these half-hourly surface energy data, which was done to reduce bias and error, rejected (i) data from periods of sensor malfunction (i.e. when there was a faulty diagnostic signal), (ii) incomplete $30 \mathrm{~min}$ data sets of $\mathrm{Rn}, \mathrm{G}$, $\mathrm{LE}$ and $\mathrm{H}$, and (iii) outliers. The data outliers were detected using the outlier detection procedure found in the Statistica software. After data screening, flux data with non-missing values of $\mathrm{Rn}, \mathrm{G}, \mathrm{LE}$, and $\mathrm{H}$ data were arranged according to monthly and seasonal periods (summer (DecemberFebruary), autumn (March-May), winter (June-August), and spring (September-November)), as well as into daytime and night-time. To be used in this study, soil heat flux was computed as a weighted mean of the three measurements, i.e. two taken under tree canopies and one on open space.

\subsubsection{Surface energy balance assessment}

The law of conservation of energy states that energy can neither be created nor destroyed, but is transformed from one form to another; hence, the ideal surface energy balance equation is written as

$\mathrm{Rn}-\mathrm{G}=\mathrm{H}+\mathrm{LE}$.

Energy imbalance occurs when both sides of the equation do not balance. The energy balance closure was evaluated at different levels, i.e. multi-year, seasonal, and day/night periods (the assumption being that daytime has positive $\mathrm{Rn}$ and night-time has negative $\mathrm{Rn}$ ), using two methods:

i. The ordinary least squares (OLS) method, which is the regression between turbulent fluxes and available energy. Ideal closure is when the intercept is zero and slope and the coefficient of determination $\left(R^{2}\right)$ are one. An assumption is made using this method, that there are no random errors in the independent variables, i.e. $\mathrm{Rn}$ and $\mathrm{G}$, which of course is a simplification.

ii. The energy balance ratio (EBR), which is ratio of the sum of turbulent fluxes to the available energy,

$$
\sum(\mathrm{LE}+\mathrm{H}) / \sum(\mathrm{Rn}-\mathrm{G}) .
$$

The EBR gives an overall evaluation of energy balance closure at longer timescales by averaging over errors in the half-hour measurements; and the ideal closure is 1. EBR has the potential to remove biases in the half-hourly data, such as the tendency to overestimate positive fluxes during the day and underestimate negative fluxes at night. We did not account for the heat storage terms in the EBR, including soil and canopy heat storage, and energy storage by photosynthesis and respiration, in this study. The significance and uncertainty associated with neglecting particularly the soil heat storage term will be discussed.
To investigate the effect of friction velocity on EBR and how it is related to time of day, using friction velocity, the half-hourly data were separated into four 25 th percentiles, and the EBR and OLS evaluated. MATLAB was used to create the graphs.

\subsubsection{Analysing surface energy partitioning}

To evaluate solar radiation variation and partitioning into latent and sensible heat fluxes in this biome, EC surface energy data from 2000 to 2014 were used. Violations in micrometeorological assumptions, instrument malfunction, and poor weather resulted in a proportion of the data being rejected. Yet, our aim was to construct continuous records of half-hourly fluxes measured by eddy covariance and compute monthly, seasonal and annual sums of surface energy fluxes. To fill the gaps in our data set, we used the Amelia II software, an R program designed to impute missing data using the expectation maximization with bootstrapping (EMB) multiple imputation algorithm (Honaker et al., 2011). The original data set is resampled using bootstrapping, after which the missing data values are imputed using the EMB algorithm. Each complete imputed data set is in such a way that the observed values are the same as those in the original data set; only the missing values are different.

The minimum, maximum and mean statistics of Rn, H, LE and $\mathrm{G}$ were then estimated. The monthly and seasonal trends of energy partitioning were assessed, and how each component is affected by vegetation dynamics at the site. Surface energy partitioning was also characterized as a direct function of VPD and Rn during the wet and dry seasons, following Gu et al. (2006).

\section{Results and discussion}

\subsection{Meteorological conditions}

Figure 1 shows the 15-year mean monthly anomalies of air temperature, VPD, and rainfall totals at the Skukuza flux tower site. The annual average temperatures over the 15year period ranged between $21.13^{\circ} \mathrm{C}$ in 2012 and $23.23^{\circ} \mathrm{C}$ in 2003 , with a 15 -year average temperature of $22.9^{\circ} \mathrm{C}$. While 2003 was the hottest year, it was also the driest year, with annual rainfall of $273.6 \mathrm{~mm}$, with 2002 also recording very low rainfall of $325.4 \mathrm{~mm}$, both receiving rainfall amounts below the recorded mean annual rainfall of $550 \pm 160 \mathrm{~mm}$. The wettest years were 2013, 2000, 2014, and 2004 which received 1414, 1115.6, 1010.2, and $1005.7 \mathrm{~mm}$, respectively. 2007 and 2008 had incomplete rainfall data records to assess their annuals. The annual daily average VPD was between 0.024 and $4.03 \mathrm{kPa}$, with an overall average of $1.28 \pm 0.62 \mathrm{kPa}$. The daily average VPD decreased with rainy days, and showed an increase during rain-free days. The wet years (i.e. 2000, 2013, and 2014) had low annual average VPD of $1.98,1.34$, and $1.83 \mathrm{kPa}$, respectively, whereas 


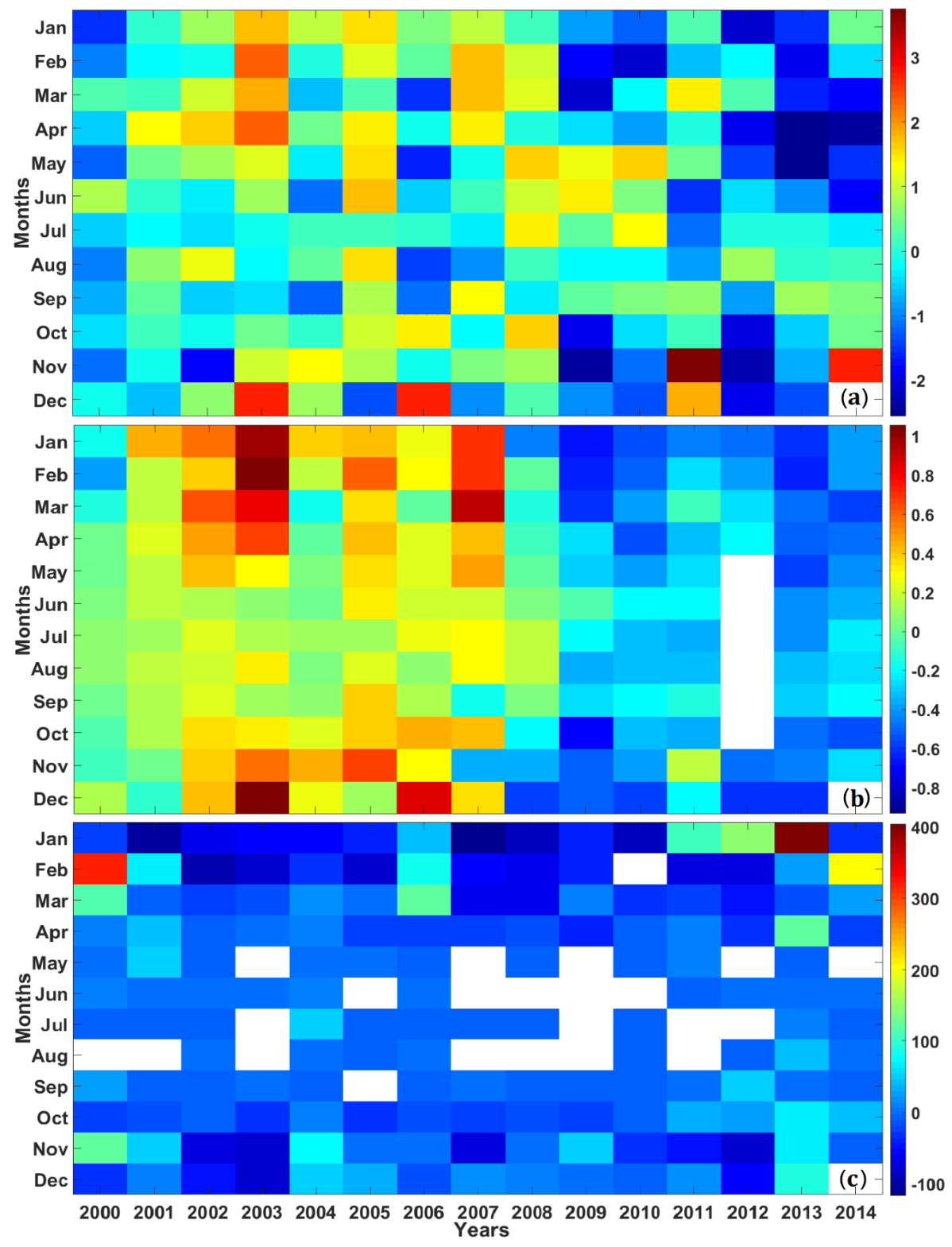

Figure 1. Summary of mean monthly anomalies of (a) air temperature, (b) VPD, and (c) rainfall from 2000 to 2014.

the drought years exhibited high VPDs with 2002 and 2003 with 2.77 and $2.97 \mathrm{kPa}$, respectively. The long-term weather records are comparable with the 1912-2001 and 1960-1999 climate analysis for the same area as reported by Kruger et al. (2002) and Scholes et al. (2001), showing a mean annual total precipitation of $547.1 \mathrm{~mm}$ and air temperature of $21.9^{\circ} \mathrm{C}$. The low rainfall during $2000-2003$ seasons was also reported by Kutch et al. (2008), who were investigating the connection between water relations and carbon fluxes during the mentioned period.

\subsection{Surface energy balance assessment}

Data completeness varied largely $7.59 \%$ (2006) and $67.97 \%$ (2013), with a mean of $34.84 \%$. The variation in data completeness is due to a number of factors including instrument failures, changes and (re)calibration, and poor weather conditions.

\subsubsection{Multi-year analysis of surface energy balance closure}

Figure 2 summarizes results of the multi-year energy balance closure analysis for the Skukuza eddy covariance system from 2000 to 2014 . The coefficient of determination $\left(R^{2}\right)$ 


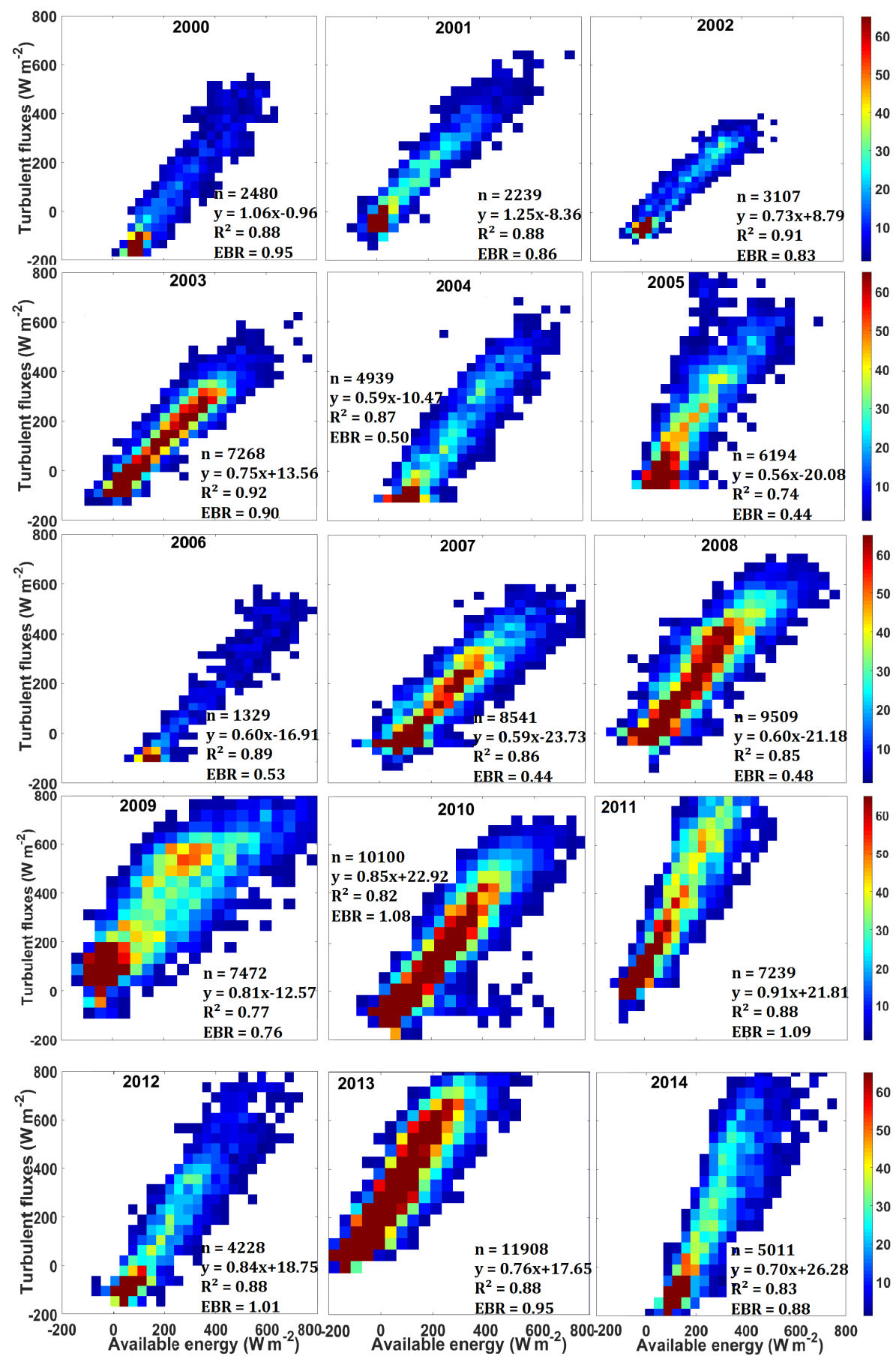

Figure 2. The 15-year series of annual regression analysis of turbulent (sensible and latent) heat fluxes against available energy (net radiation minus ground heat flux) from 2000 to 2014 at Skukuza (SA). The colour bars represent the count of EBR values.

for the 15-year period varied between 0.74 and 0.92 , with a mean value of $0.85 \pm 0.06$. The slopes ranged between 0.56 and 1.25 , with a mean $0.77 \pm 0.19$, while the intercepts varied from -23.73 to 26.28 , with a mean of 1.03 and standard deviation of $18.20 \mathrm{~W} \mathrm{~m}^{-2}$. The annual energy balance ratio (EBR) for the 15 years extended between 0.44 in 2005 and 2007 and 1.09 in 2011, with a mean of $0.78 \pm 0.24$. Between
2004 and 2008, EBR ranged between 0.44 and 0.53 , whereas from 2000 to 2003 and 2009 to 2014, the EBR was between 0.76 and 1.09 . The EBRs for 2010 to 2012 were slightly greater than 1 (1.08, 1.09 and 1.01 , respectively), indicating an overestimation of the turbulent fluxes (H + LE) compared to the available energy; this still giving the absolute imbalance values of within $30 \%$. The remaining years, 2000 
2003 and 2009, were less than 1, indicating that the turbulent fluxes were lower than the available energy. The further away the slope is from unity, the lower the EBR, as shown by the low slope values between 2004 and 2008. The period of low EBR between 2004 and 2008 is characterized by the absence of negative values of available energy $(\mathrm{Rn}-\mathrm{G})$ as illustrated in Fig. 2. Between 2000 and 2004, the CNR2 net radiometer was used to measure long- and shortwave radiation, and these were combined to derive Rn. However, when the pyrgeometer broke down in 2004, Rn was derived from measured shortwave radiation and modelled longwave radiation until the CNR2 was replaced by the NR-Lite net radiometer in 2009. This was a significant source of error, as shown by the low EBR between 2004 and 2008. The closed-path gas analyser was also changed to open-path gas analyser in 2006. An analysis of the 2006 data (which had very low data completeness of $7.59 \%$ ) showed that there were no measurements recorded until September, possibly due to instrument failure. Further analysis and discussion of the EBR was done with the exclusion of years with low-quality data.

Our final mean multi-year EBR estimate, excluding the years with poor data quality (2004-2008), was therefore $0.93 \pm 0.11$, ranging between 0.76 and 1.09 . The $R^{2}$ for these years varied between 0.77 and 0.92 , with a mean value of $0.87 \pm 0.05$. The slopes were from 0.7 to 1.25 , with a mean $0.87 \pm 0.17$, while the intercepts varied from -12.57 to 26.28 , with a mean of 10.79 and standard deviation of $13.67 \mathrm{~W} \mathrm{~m}^{-2}$.

The EBR results for the Skukuza eddy covariance system, which vary between 0.76 and 1.09 with an annual mean of 0.93 (only the years with high-quality data), are generally within the reported accuracies as shown in most studies that report the energy balance closure error at 10-30\%, across different ecosystems. For instance, Wilson et al. (2002) also recorded an annual mean EBR of 0.84, ranging between 0.34 and 1.69 in an extensive study investigating 22 FLUXNET sites across the globe; EBR in ChinaFLUX sites ranged between 0.58 and 1.00 , with a mean of 0.83 (Yuling et al., 2005); according to Were et al. (2007), EBR values of about 0.90 were found over shrub and herbaceous patches in a dry valley in southeast Spain, whereas Chen et al. (2009) showed a mean of 0.98 EBR for their study in the semi-arid region of Mongolia, and an EBR value of 0.80 was found by Xin and Liu (2010) in a maize crop in semi-arid conditions, in China. Using data from the Tibetan Observation and Research Platform (TORP), Liu et al. (2011) observed an EBR value of 0.85 in an alfalfa field in semi-arid China.

\subsubsection{Seasonal variation of EBR}

Figure 3 shows the seasonal OLS results for the 15-year period, excluding years 2004 to 2008. The slopes ranged between 0.67 and 0.87 , with a mean of $0.78 \pm 0.08$, and the intercepts were a mean of $19.13 \pm 16.30 \mathrm{~W} \mathrm{~m}^{-2} . R^{2}$ ranged between 0.81 and 0.88 with a mean of $0.84 \pm 0.04$. The EBR

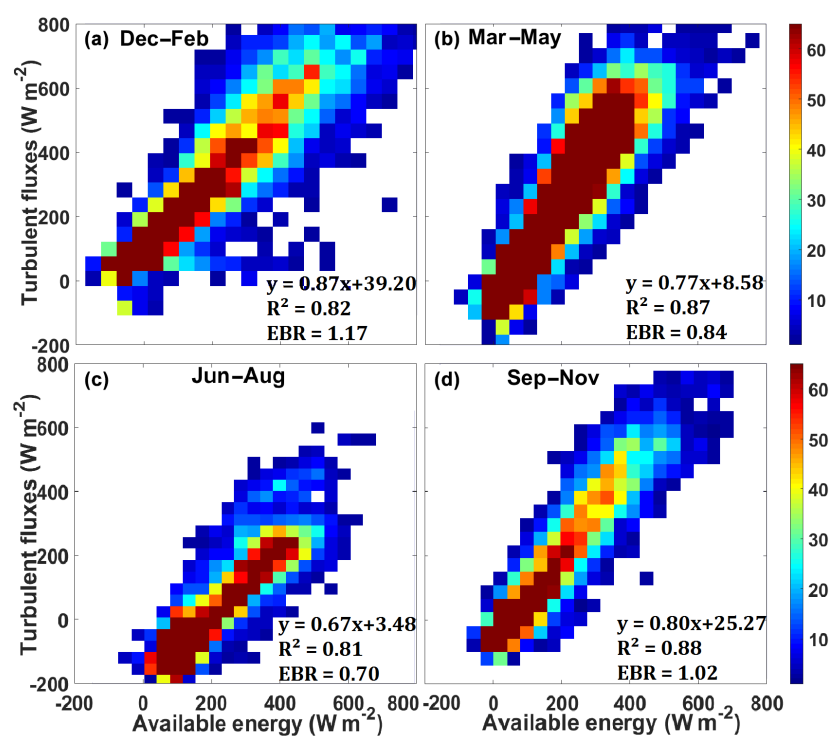

Figure 3. Seasonal turbulent fluxes $(H+L E)$ correlation to available energy $(\mathrm{Rn}-\mathrm{G})$ for Skukuza flux tower from summer (December-February), autumn (March-May), winter (JuneAugust), and spring (September-November). The colour bars represent the count of EBR values.

for the different seasons ranged between 0.70 and 1.12, with a mean of $0.92 \pm 0.19$. The dry season had the lowest EBR of 0.70 , while summer recorded 1.02 , and spring were closest to unity with EBR of and 1.12, respectively, and autumn had EBR of 0.84. A large number of outliers is observed in summer due to cloudy weather conditions and rainfall events that make the thermopile surface wet, thus reducing the accuracy of the net radiometer. A study comparing different the performance of different net radiometers by Blonquist et al. (2009) shows that the NR-Lite is highly sensitive to precipitation and dew/frost since the sensor is not protected.

The results of our study concur with similar studies that assessed the seasonal variation of EBR. For instance, Wilson et al. (2002) comprehensively investigated the energy closure of the summer and winter seasons for 22 FLUXNET sites for 50 site-years. They also reported higher energy balance correlation during the wet compared to the dry season, with the mean $R^{2}$ of 0.89 and 0.68 , respectively. Whereas our results show significant differences between the wet (1.12) and dry (0.70), their EBR showed smaller differences between the two seasons, being 0.81 and 0.72 , for summer and winter, respectively. Ma et al. (2009) reported an opposite result from the Skukuza results, showing energy closures of 0.70 in summer and 0.92 in winter over the flat prairie on the northern Tibetan Plateau.

\subsubsection{Day-night-time effects}

Figure 4 shows the daytime and nocturnal OLS regression results for the 15 -year period. The daytime and nocturnal 


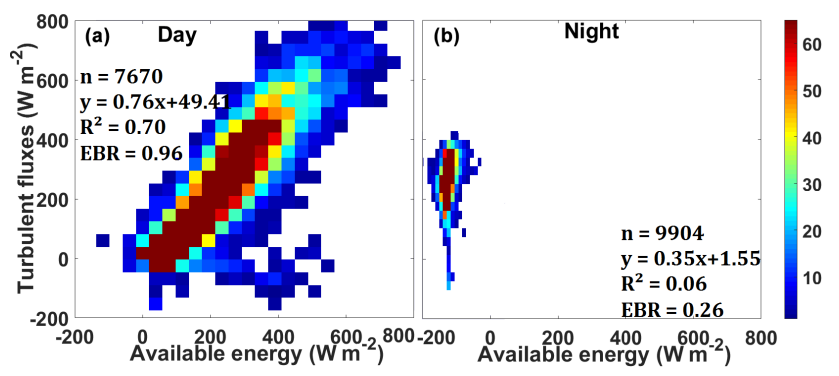

Figure 4. Turbulent fluxes correlation to available energy for daytime (a) and night-time (b), using the full (2000-2014) 15-year available data series. The colour bars represent the count of EBR values.

slopes were 0.99 and 0.11 , with the intercepts being 76.76 and $1.74 \mathrm{~W} \mathrm{~m}^{-2}$, respectively. Daytime and nocturnal $R^{2}$ were 0.64 and 0.01 , respectively. The EBRs for the different times of day were 0.96 and 0.27 , daytime and nocturnal, respectively.

Other studies also reported a higher daytime surface energy balance closure. For instance, Wilson et al. (2002) showed that the mean annual daytime EBR was 0.8 , whereas the nocturnal EBR was reported to be was negative or was much less or much greater than 1 .

To understand the effect of friction velocity on the energy balance closure, surface energy data which had corresponding friction velocity $\left(u_{*}\right)$ data were analysed. Using friction velocity, the data were separated into four 25th percentiles, and the EBR and OLS evaluated. Results show that the first quartile, the EBR was 3.94, with the 50th percentile at 0.99, the third quartile at unity, and the fourth quartile at 1.03 (Fig. 5). The slopes were between 1.01 and 1.12, with the intercepts ranging between -9.26 and $-0.17 \mathrm{~W} \mathrm{~m}^{-2}$, whereas $R^{2}$ were $0.82,0.86,0.85$, and 0.81 for the first to the fourth quartiles, respectively.

An assessment shows that the time associated with the low friction velocities, i.e. the first quartile are night-time data constituting $81 \%$ of the whole first quartile data set, and the last quartile had the highest number of daytime values at $79.29 \%$ of the fourth quartile data set. Lee and Hu (2002) hypothesized that the lack of energy balance closure during nocturnal periods was often the result of mean vertical advection, whereas Aubinet et al. (1999) and Blanken et al. (1997) showed that energy imbalance during nocturnal periods is usually greatest when friction velocity is small. Another source of error in the nocturnal EBR is the high uncertainty in night-time measurements of Rn. At night, the assumption is that there is no shortwave radiation, and $\mathrm{Rn}$ is a product of longwave radiation. Studies show that night-time measurements of longwave radiation were less accurate than daytime measurements (Blonquist et al., 2009). The RN-Lite, for instance, has low sensitivity to longwave radiation, resulting in low accuracy in low measurements.

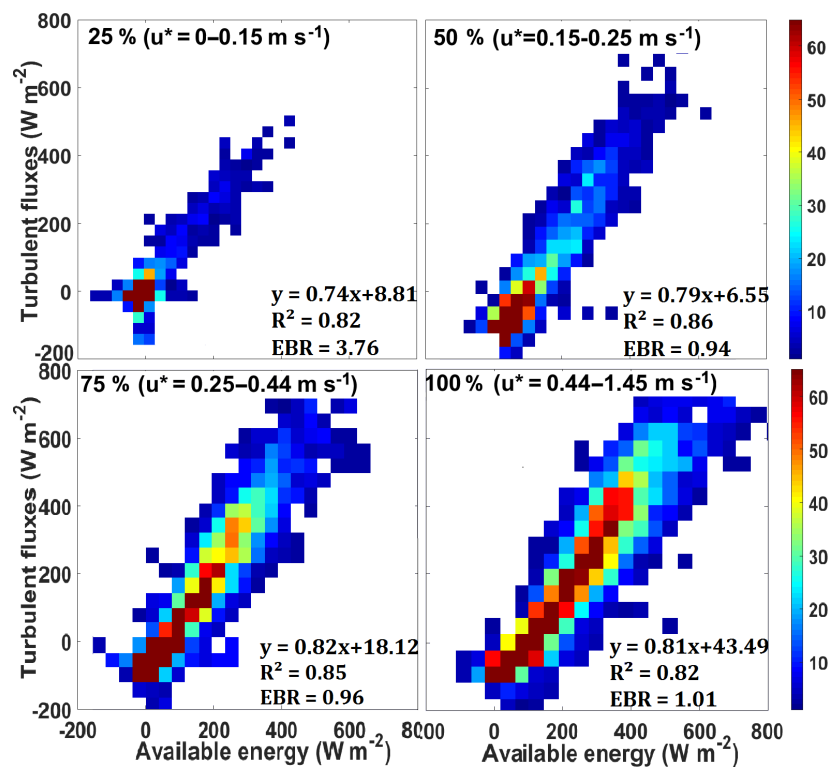

Figure 5. OLS and EBR evaluations at different friction velocity sorted at four quartiles. The colour bar represents the count of EBR values. The colour bars represent the count of EBR values.

Soil heat flux (G) plays a significant role in the surface energy balance as it determined how much energy is available for the turbulent fluxes, especially in areas with limited vegetation cover. Its exclusion in surface energy balance studies results not only in the overestimation of the available energy, but also the overestimation of the EBR. In this study, we examined how inclusion and exclusion of $\mathrm{G}$ impacts the surface energy balance closure. When $\mathrm{G}$ was excluded in the calculation, the multi-year EBR ranged between 0.73 and 1.07, with an annual mean EBR of $0.90 \pm 0.11$, which is about $3 \%$ lower than the initial EBR $(0.93 \pm 0.11)$. While the initial daytime EBR was 0.96 , it was 0.87 when $\mathrm{G}$ was excluded, which is a decrease of approximately $10 \%$. The night-time EBR was 0.13 , as low as $50 \%$ of the initial EBR (0.26), showing that $G$ has greater significance on the surface energy balance at night. These results are in agreement with other studies. For instance, Ogée et al. (2001) showed that soil heat flux represents up to $50 \%$ of net radiation at midday and up to $80 \%$ during night-time. Stull (2012) also reported that during daytime $\mathrm{G}$ only accounts for $5-15 \%$ of net radiation, whereas at night it is up to $50 \%$.

While $\mathrm{G}$ is an important component of the surface energy balance, our study ignored the different energy storage terms in determining the EBR, including the soil heat storage term. The exclusion of the soil heat storage term results in the underestimation of $\mathrm{G}$, as the real value of $\mathrm{G}$ is a combination of the flux measured by the plate and the heat exchange between the ground and the depth of the plate. This in turn contributes to the overestimation of the available energy, which then lowers the EBC. Among other factors (vegetation cover, soil moisture, and temperature), this storage term varies with the 
depth of the soil heat flux plate as demonstrated by Ochsner et al. (2006), who reported that at a depth of $1 \mathrm{~cm}$, the maximum $\mathrm{G}$ is up to $13 \%$ less than the maximum surface value, and at $10 \mathrm{~cm}$ maximum $\mathrm{G}$ is up to $70 \%$ less than the surface value; thus, its exclusion results in similar error margins in the EBC. As reported by different studies, the omission of the soil heat storage results in the underestimation of the energy EBC by up to $7 \%$. For instance, Liu et al. (2017) reported an increase in OLS slope of an average $8.8 \%$ and a mean daily EBR increase of $5 \%$ when the soil heat storage term was considered in their study in the Taihu Lake region of the Southern China Plain. In their study in the three sites in the Badan Jaran desert, Li et al. (2014) analysed the effect of including soil heat storage derived by different methods in the energy balance closure; their EBR improved by between 1.5 and $4 \%$. Zuo et al. (2011) reported an improvement of 6 to $7 \%$ when they included the soil heat storage in their calculation of EBR, at the Semi-Arid Climate and Environment Observatory of Lan-Zhou University (SACOL) site in semi-arid grassland over the Loess Plateau of China. The improvement of the EBR in the study in a FLUXNET boreal site in Finland by Sánchez et al. (2010) was shown to be $3 \%$ when the soil heat storage was included, which increased to $6 \%$ when other storage terms (canopy air) were taken into account.

\subsection{Surface energy partitioning}

\subsubsection{Surface energy measurements}

The mean daily and annual measurements of the energy budget components from 2000 to 2014 are highlighted in Fig. 6 and Table 2. The seasonal cycle of each component can be seen throughout the years, where at the beginning of each year the energy budget components are high, and as each year progresses they all decrease to reach a low during the middle of the year, which is the winter/dry season, and a gradual increase being experienced during spring right to the summer at the end of each year. The multi-year daily means of Rn, H, LE, and G were 139.1, 57.70, 42.81, and $2.94 \mathrm{~W} \mathrm{~m}^{-2}$, with standard deviations of $239.75,104.15$, 70.58 , and $53.67 \mathrm{~W} \mathrm{~m}^{-2}$, respectively.

The gaps in 2006 indicate the absence of the surface energy flux measurements in those years, which was a result of instrument failure. Between 2004 and 2008, the Rn was calculated as a product of measured shortwave radiation and modelled longwave radiation, which was a high source of error in the estimation of Rn. These years are also characterized by poor energy balance closure, as shown in Sect. 3.2.1 above.

\subsubsection{Influence of weather conditions and seasonality}

In arid/semi-arid ecosystems, solar radiation is not a limiting factor for latent heat flux, instead it is mainly limited by
Table 2. Statistical summary of annual values of the energy balance components.

\begin{tabular}{|c|c|c|c|c|c|c|}
\hline Year & $\begin{array}{r}\% \text { data } \\
\text { completion }\end{array}$ & & $\mathrm{H}$ & LE & $\mathrm{G}$ & $\mathrm{Rn}$ \\
\hline \multirow[t]{3}{*}{2000} & 14.16 & $\operatorname{Max}$ & 470.31 & 422.89 & 191.53 & 817.60 \\
\hline & & Min & -139.77 & -72.43 & -61.60 & -95.93 \\
\hline & & Mean & 45.82 & 36.11 & 5.32 & 91.46 \\
\hline \multirow[t]{3}{*}{2001} & 12.78 & $\operatorname{Max}$ & 790.82 & 513.09 & 292.87 & 899.90 \\
\hline & & Min & -159.87 & -85.95 & -90.27 & -116.58 \\
\hline & & Mean & 58.56 & 43.68 & 9.27 & 128.27 \\
\hline \multirow[t]{3}{*}{2002} & 17.77 & $\operatorname{Max}$ & 415.93 & 174.07 & 171.93 & 583.30 \\
\hline & & Min & -117.66 & -89.16 & -86.00 & -122.21 \\
\hline & & Mean & 61.35 & 10.29 & 4.10 & 90.72 \\
\hline \multirow[t]{3}{*}{2003} & 41.50 & $\operatorname{Max}$ & 556.21 & 308.71 & 217.60 & 879.30 \\
\hline & & Min & -92.99 & -97.81 & -106.23 & -116.04 \\
\hline & & Mean & 58.15 & 21.68 & 6.17 & 94.53 \\
\hline \multirow[t]{3}{*}{2004} & 28.21 & Max & 505.36 & 498.10 & 129.96 & 925.30 \\
\hline & & Min & -150.08 & -89.07 & -69.76 & -5.88 \\
\hline & & Mean & 56.46 & 17.99 & 7.97 & 156.10 \\
\hline \multirow[t]{3}{*}{2005} & 35.37 & $\operatorname{Max}$ & 606.28 & 737.43 & 288.20 & 933.20 \\
\hline & & Min & -130.40 & -97.00 & -107.37 & -4.92 \\
\hline & & Mean & 51.43 & 17.82 & 0.99 & 159.09 \\
\hline \multirow[t]{3}{*}{2006} & 7.59 & $\operatorname{Max}$ & 583.66 & 331.25 & 335.30 & 1003.30 \\
\hline & & Min & -72.45 & -119.09 & -72.80 & -6.56 \\
\hline & & Mean & 84.67 & 35.94 & 19.69 & 247.70 \\
\hline \multirow[t]{3}{*}{2007} & 48.77 & $\operatorname{Max}$ & 552.93 & 426.34 & 340.67 & 1011.30 \\
\hline & & Min & -131.40 & -130.79 & -129.70 & -6.71 \\
\hline & & Mean & 59.04 & 14.32 & 4.14 & 169.84 \\
\hline \multirow[t]{3}{*}{2008} & 54.30 & $\operatorname{Max}$ & 616.43 & 439.76 & 238.57 & 1038.50 \\
\hline & & Min & -140.13 & -144.97 & -104.60 & -5.91 \\
\hline & & Mean & 63.06 & 26.30 & 6.22 & 191.26 \\
\hline \multirow[t]{3}{*}{2009} & 42.69 & Max & 551.34 & 776.62 & 328.93 & 1060.50 \\
\hline & & Min & -96.68 & -135.43 & -94.20 & -155.90 \\
\hline & & Mean & 55.42 & 96.54 & 6.87 & 207.77 \\
\hline \multirow[t]{3}{*}{2010} & 57.65 & Max & 626.68 & 624.38 & 199.33 & 888.00 \\
\hline & & Min & -173.11 & -135.62 & -66.35 & -180.70 \\
\hline & & Mean & 57.23 & 52.54 & 3.74 & 105.10 \\
\hline \multirow[t]{3}{*}{2011} & 41.34 & Max & 591.16 & 688.46 & 171.27 & 832.00 \\
\hline & & Min & -135.77 & -127.02 & -58.59 & -96.50 \\
\hline & & Mean & 63.88 & 73.11 & 1.75 & 127.94 \\
\hline \multirow[t]{3}{*}{2012} & 27.62 & Max & 572.11 & 566.88 & 185.80 & 899.00 \\
\hline & & Min & -171.83 & -148.49 & -50.92 & -99.69 \\
\hline & & Mean & 59.25 & 52.49 & 2.16 & 111.31 \\
\hline \multirow[t]{3}{*}{2013} & 67.97 & Max & 570.79 & 665.48 & 146.03 & 845.58 \\
\hline & & Min & -197.40 & -149.10 & -55.36 & -107.70 \\
\hline & & Mean & 50.25 & 38.63 & -1.22 & 92.80 \\
\hline \multirow[t]{3}{*}{2014} & 28.66 & $\operatorname{Max}$ & 533.46 & 726.31 & 89.50 & 893.00 \\
\hline & & Min & -238.65 & -134.39 & -33.36 & -89.70 \\
\hline & & Mean & 59.37 & 69.55 & 1.18 & 147.30 \\
\hline
\end{tabular}

water availability. The seasonal fluctuations of energy fluxes are affected by the seasonal changes in the solar radiation, air temperature, precipitation, and soil moisture (Baldocchi et al., 2001; Arain et al., 2003). These climatic variables influence vegetation dynamics in an ecosystem, as well as how solar radiation is partitioned. Hence, daily measurements of precipitation, air temperature, and VPD were evaluated to investigate the partitioning of the surface energy in the semiarid savanna landscape of Skukuza. 

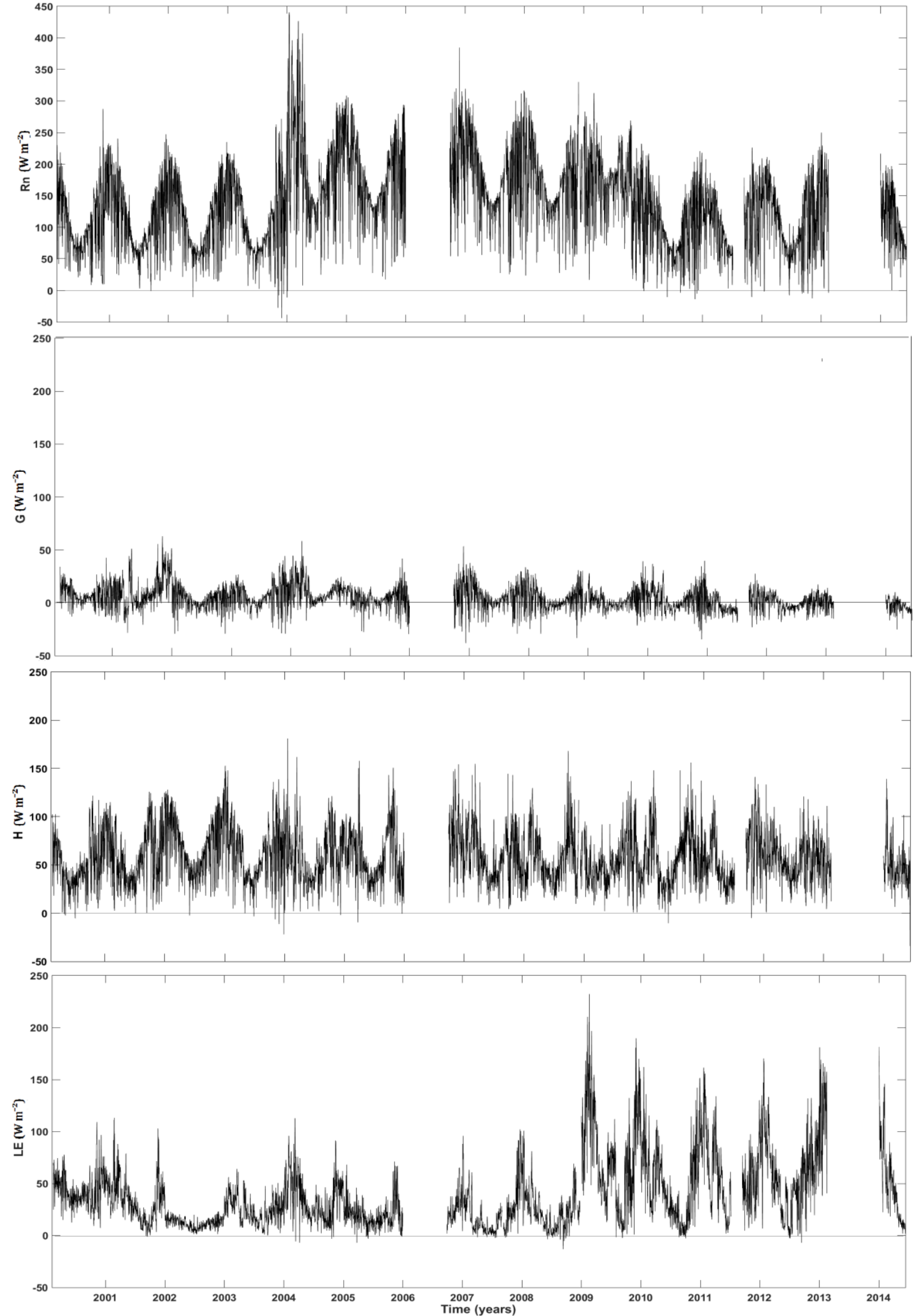

Figure 6. Time series of daily mean surface energy balance component fluxes from 2000 to 2014 at Skukuza flux tower site (SA). 


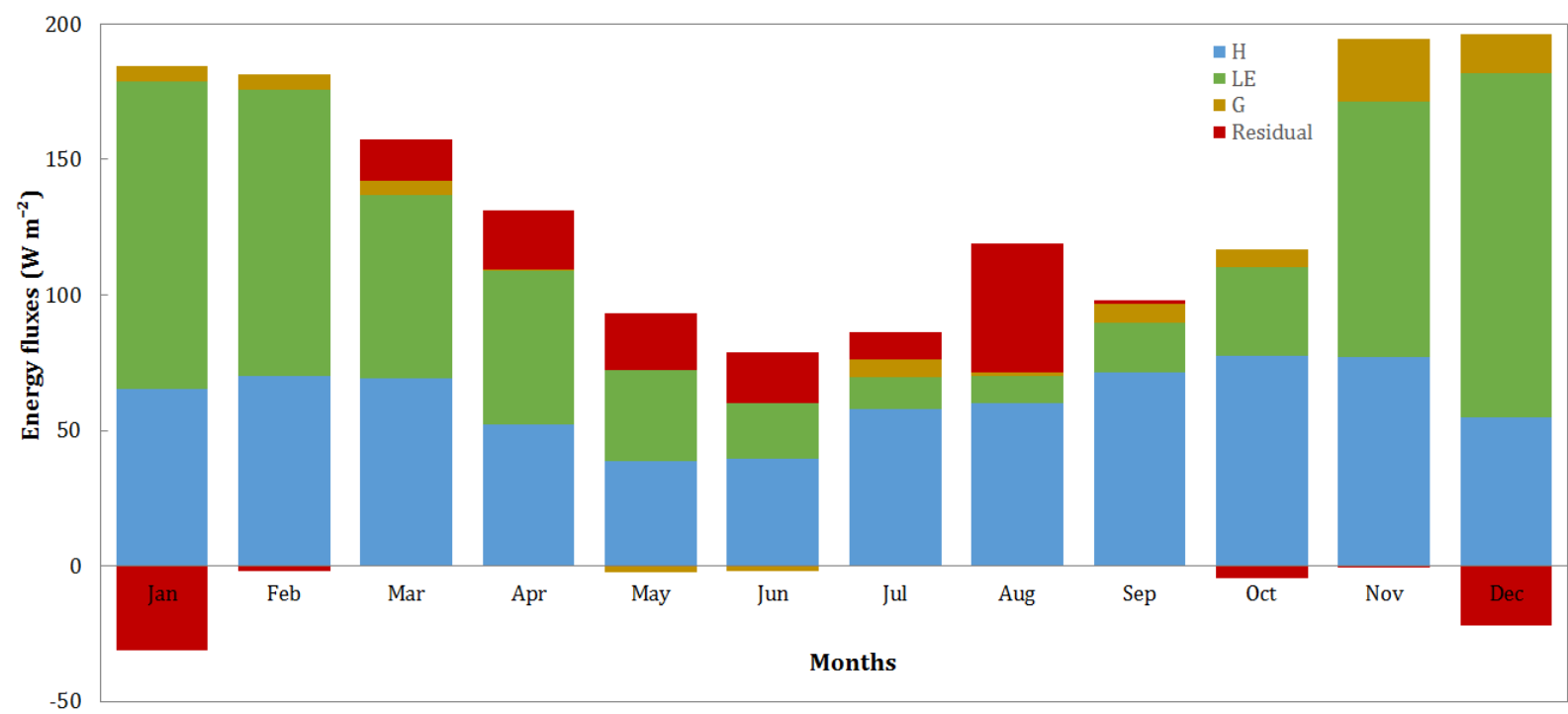

Figure 7. The 15-year (2000-2014) monthly means of surface energy balance fluxes of Skukuza flux tower site (SA), highlighting the partitioning of $\mathrm{Rn}$.

To illustrate the partitioning of solar radiation into the different fluxes throughout the year, Fig. 7 presents the multiyear mean monthly variations of the surface energy components showing a general decrease in the components between February and June, which then gradually increases again until November. The multi-year monthly means of Rn, H, LE, and $\mathrm{G}$ were $71.27 \mathrm{~W} \mathrm{~m}^{-2}$ (June) and $197.33 \mathrm{~W} \mathrm{~m}^{-2}$ (November), $37.11 \mathrm{~W} \mathrm{~m}^{-2}$ (June) and $80.37 \mathrm{~W} \mathrm{~m}^{-2}$ (November), $8.52 \mathrm{~W} \mathrm{~m}^{-2}$ (August) and $127.17 \mathrm{~W} \mathrm{~m}^{-2}$ (December), $-2.28 \mathrm{~W} \mathrm{~m}^{-2}$ (June) and $20.78 \mathrm{~W} \mathrm{~m}^{-2}$ (November), respectively. The month of August had the highest BR of 6.42, whereas December had the least at 0.42 . The residual accounted for between -19.69 and $34.74 \%$ of $\mathrm{Rn}$, and an average of $4.70 \%$.

The general trend shows that sensible heat flux dominated the energy partitioning between May and October, followed by latent heat flux, and lastly the soil heat flux, except during the wet season where latent heat flux was larger than sensible heat flux. This is illustrated by the trend of BR, showing an increase from April, with the peak in August, then a steady decrease until it hits lowest in December. The period of low $\mathrm{BR}$ is characterized by high Rn and high precipitation. As the season transitions into the dry season, it is characterized by reduced net radiation and low measurements $\mathrm{H}$ and LE.

Just before the first rains, i.e. between September and November, tree flowering and leaf emergence occurs in the semi-arid savanna in the Skukuza area (Archibald and Scholes, 2007), and grasses shoot as soil moisture availability improves with the rains (Scholes et al., 2003). This is characterized by a gradual increase in LE and decrease in BR, which, when compared to the dry season, is significantly lower than the $\mathrm{H}$, as illustrated in Fig. 7. As the rainy season progresses, and vegetation development peaks, LE also reaches its maximum, becoming significantly higher than $\mathrm{H}$, and hence low BR. Between March and September, when leaf senescence occurs, the leaves gradually change colour to brown and grass to straw, and trees defoliate, $\mathrm{H}$ again gradually becomes significantly higher than LE.

The influence of VPD and Rn on surface energy partitioning was investigated during the wet and dry seasons. Results show that during both periods there is an increase in $\mathrm{H}$ and decrease in LE with an increase in VPD; although the gradient of LE decrease differ significantly during the two periods, $\mathrm{H}$ increases similarly during both the wet and dry periods (Fig. 8). VPD is higher in times of little or no rain (low soil water availability), which explains the decrease in LE with a rise in VPD. In this instance, although the evaporative demand is high, the stomatal conductance is reduced due to absence of water in the soil, resulting in smaller LE and higher $\mathrm{H}$. Rn, on the other hand, is partitioned into different fluxes, based on other climatic and vegetation physiological characteristics. Figure 9 illustrates that both $\mathrm{LE}$ and $\mathrm{H}$ increase with increase in $\mathrm{Rn}$, although their increases are not in proportion, based on season. During the wet season, the rate of increase in LE is higher than that of $\mathrm{H}$, whereas in the dry season the reverse is true. The rate of increase in LE is controlled by the availability of soil water (precipitation), (also illustrated in Fig. 6 (LE)), and during the wet season it increases steadily with increasing Rn, whereas the rate of increase in $\mathrm{H}$ is concave, showing saturation with an increase in $\mathrm{Rn}$. The opposite is true during the dry season, with limited water availability, where the rate of increase in LE slows down with increase in $\mathrm{Rn}$, and there is a steady increase in $\mathrm{H}$ with Rn increase.

Our study results are consistent with similar studies, for example Gu et al. (2006), who examined how soil moisture, 

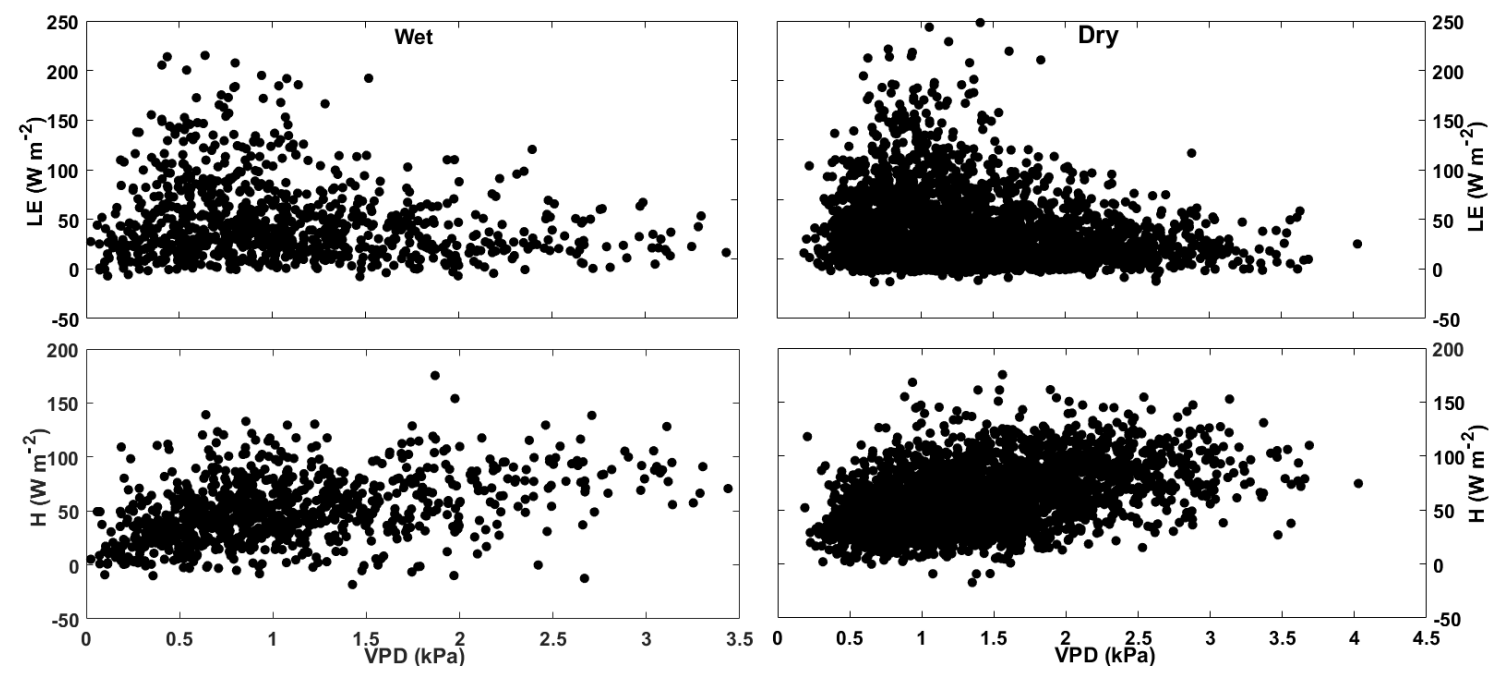

Figure 8. Relationship between the fluxes and VPD under wet and dry conditions.
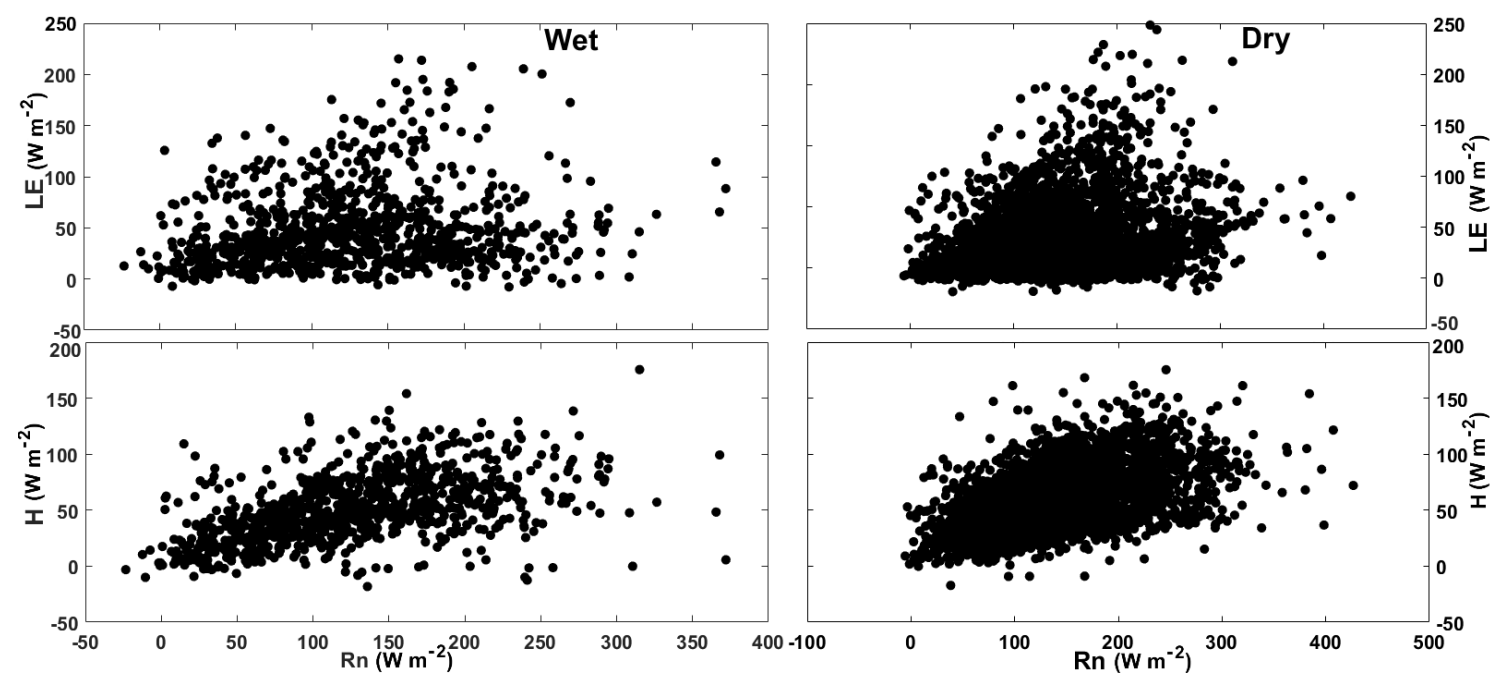

Figure 9. Effects of net radiation on LE and $\mathrm{H}$ under wet and dry conditions.

VPD, and net radiation control surface energy partitioning at a temperate deciduous forest site in central Missouri, USA. Both studies agree that with ample soil moisture, during the rainy season, latent heat flux dominates over sensible heat flux, and reduced soil water availability reversed the dominance of latent heat over sensible heat, because of its direct effect on stomatal conductance. An increase in net radiation, on the other hand, also increases both sensible and latent heat fluxes. The increase in either then becomes a function of soil moisture availability, since they cannot increase in the same proportion. However, whereas we found that a rise in VPD is characterized by a decrease in LE and an increase in $\mathrm{H}$ in both periods, their findings show a significant increase in LE and decrease in $\mathrm{H}$ with a rise in VPD during the non-drought period, with both components showing slight increases with increase in VPD in dry conditions. Li et al. (2006) also investigated the partitioning of surface energy in the grazing lands of Mongolia, and concluded that the energy partitioning was also controlled by vegetation dynamics and soil moisture availability, although soil heat flux is reportedly higher than latent heat flux in most instances. In a temperate mountain grassland in Austria, Hammerle et al. (2008) found that the energy partitioning in this climatic region was dominated by latent heat flux, followed by sensible heat flux and lastly soil heat flux.

The consensus in all above studies is that vegetation and climate dynamics play a critical role in energy partitioning. They note that during full vegetation cover, latent heat flux is the dominant portion of net radiation. However, depending on the climatic region, the limiting factors of energy partitioning vary between water availability and radiation. Our study confirms that in semi-arid regions, sensible heat flux 
is the highest fraction of net radiation throughout the year, except during the wet period, when latent heat flux surpasses sensible heat flux. However, in regions and locations where water availability is not a limiting factor, latent heat flux may take the highest portion of net radiation.

\section{Conclusion}

This study investigated both surface energy balance closure and how this energy is partitioned into turbulent fluxes during the wet and dry seasons in a semi-arid savanna ecosystem in Skukuza using eddy covariance data from 2000 to 2014. The analysis revealed a mean multi-year energy balance ratio of $0.93 \pm 0.11$, i.e. excluding years of low-quality data. The variation of EBR based on season, time of day, and as a function of friction velocity was also explored. The seasonal EBR varied between 0.70 and 1.12, with the dry season recording the highest energy imbalance. Daytime EBR was as high as 0.96 , compared with $0.27 \mathrm{EBR}$ for the night-time. The high energy imbalance at night was explained as a result of stable conditions, which limit turbulence that is essential for the creation of eddies. The assessment of the effect of friction velocity on EBR showed that EBR increased with an increase in friction velocity, with low friction velocity experienced mainly during night-time. Furthermore, the impact of $\mathrm{G}$ in this biome on EBR, with results showing a decrease of up to $7 \%$, with an annual mean of $3.13 \pm 2.70$, in EBR when $\mathrm{G}$ was excluded in the calculation of EBR.

The energy partition analysis revealed that sensible heat flux is the dominant portion of net radiation in this semiarid region, except during the rainfall period. The results also show that water availability and vegetation dynamics play a critical role in energy partitioning, whereby when it rains, vegetation growth occurs, leading to an increase in latent heat flux/evapotranspiration. Clearly an increase in $\mathrm{Rn}$ results in a rise in both $\mathrm{H}$ and LE; however, either increase is controlled by water availability. During the wet season, the rate of increase in LE is higher than that of $\mathrm{H}$, whereas in the dry season the reverse is true. The rate of increase in LE is controlled by the availability of soil water (precipitation), and during the wet season it increases steadily with increasing $\mathrm{Rn}$, whereas the rate of increase in $\mathrm{H}$ shows saturation with an increase in $\mathrm{Rn}$. The opposite is true during the dry season - with limited water availability, the rate of increase in LE reaches saturation with increase in $\mathrm{Rn}$ and a steady increase in $\mathrm{H}$ with $\mathrm{Rn}$ increase. An increase in VPD, on the other hand, results in an increase in $\mathrm{H}$ and decrease in LE, with higher VPD experienced during the dry season, which explains the high $\mathrm{H}$, although the evaporative demand is high.
Data availability. The dataset used in this study is available as a supplement to this paper. Alternatively, it can be accessed via http: //gaia.agraria.unitus.it/home/site-details?id=178 and http://fluxnet. fluxdata.org/.

\section{The Supplement related to this article is available online at https://doi.org/10.5194/hess-21-3401-2017- supplement.}

Competing interests. The authors declare that they have no conflict of interest.

Acknowledgements. This study was supported by the Council for Scientific and Industrial Research under the project entitled "Monitoring of water availability using geo-spatial data and earth observations", and the National Research Foundation under the Thuthuka PhD cycle grant.

Edited by: Alexander Loew

Reviewed by: Nick van de Giesen and one anonymous referee

\section{References}

Arain, M., Black, T., Barr, A. G., Griffis, T., Morgenstern, K., and Nesic, Z.: Year-round observations of the energy and water vapour fluxes above a boreal black spruce forest, Hydrol. Proc., 17, 3581-3600, 2003.

Archibald, S. and Scholes, R.: Leaf green-up in a semi-arid African savanna-separating tree and grass responses to environmental cues, J. Veg. Sci., 18, 583-594, 2007.

Archibald, S. A., Kirton, A., van der Merwe, M. R., Scholes, R. J., Williams, C. A., and Hanan, N.: Drivers of inter-annual variability in Net Ecosystem Exchange in a semi-arid savanna ecosystem, South Africa, Biogeosciences, 6, 251-266, https://doi.org/10.5194/bg-6-251-2009, 2009.

Aubinet, M., Grelle, A., Ibrom, A., Rannik, Ü., Moncrieff, J., Foken, T., Kowalski, A. S., Martin, P. H., Berbigier, P., and Bernhofer, C.: Estimates of the annual net carbon and water exchange of forests: The EUROFLUX methodology, Adv. Ecol. Res., 30, 113-175, 1999.

Bagayoko, F., Yonkeu, S., Elbers, J., and van de Giesen, N.: Energy partitioning over the West African savanna: Multi-year evaporation and surface conductance measurements in eastern Burkina Faso, J. Hydrol., 334, 545-559, 2007.

Baldocchi, D., Falge, E., Gu, L., Olson, R., Hollinger, D., Running, S., Anthoni, P., Bernhofer, C., Davis, K., and Evans, R.: FLUXNET: A new tool to study the temporal and spatial variability of ecosystem-scale carbon dioxide, water vapor, and energy flux densities, B. Am. Meteorol. Soc., 82, 2415-2434, 2001.

Barr, A. G., van der Kamp, G., Black, T. A., McCaughey, J. H., and Nesic, Z.: Energy balance closure at the BERMS flux towers in relation to the water balance of the White Gull Creek watershed 1999-2009, Agr. Forest Meteorol., 153, 3-13, 2012.

Blanken, P. D., Black, T. A., Yang, P. C., Neumann, H. H., Nesic, Z., Staebler, R., Den Hartog, G., Novak, M. D., and Lee, X.: 
Energy balance and canopy conductance of a boreal aspen forest: Partitioning overstory and understory components, J. Geophys. Res.-Atmos., 102, 28915-28927, 1997.

Blonquist, J., Tanner, B., and Bugbee, B.: Evaluation of measurement accuracy and comparison of two new and three traditional net radiometers, Agr. Forest Meteorol., 149, 1709-1721, 2009.

Chen, S., Chen, J., Lin, G., Zhang, W., Miao, H., Wei, L., Huang, J., and Han, X.: Energy balance and partition in Inner Mongolia steppe ecosystems with different land use types, Agr. Forest Meteorol., 149, 1800-1809, 2009.

Eugster, W. and Senn, W.: A cospectral correction model for measurement of turbulent $\mathrm{NO}_{2}$ flux, Bound.-Lay. Meteorol., 74, 321340, 1995.

Falge, E., Reth, S., Brüggemann, N., Butterbach-Bahl, K., Goldberg, V., Oltchev, A., Schaaf, S., Spindler, G., Stiller, B., and Queck, R.: Comparison of surface energy exchange models with eddy flux data in forest and grassland ecosystems of Germany, Ecol. Model., 188, 174-216, 2005.

Foken, T., Mauder, M., Liebethal, C., Wimmer, F., Beyrich, F., Leps, J.-P., Raasch, S., DeBruin, H. A. R., Meijninger, W. M. L., and Bange, J.: Energy balance closure for the LITFASS-2003 experiment, Theor. Appl. Climatol., 101, 149-160, 2010.

Franssen, H., Stöckli, R., Lehner, I., Rotenberg, E., and Seneviratne, S.: Energy balance closure of eddy-covariance data: A multisite analysis for European FLUXNET stations, Agr. Forest Meteorol., 150, 1553-1567, 2010.

Gu, L., Meyers, T., Pallardy, S. G., Hanson, P. J., Yang, B., Heuer, M., Hosman, K. P., Riggs, J. S., Sluss, D., and Wullschleger, S. D.: Direct and indirect effects of atmospheric conditions and soil moisture on surface energy partitioning revealed by a prolonged drought at a temperate forest site, J. Geophys. Res.-Atmos., 111, D16102, https://doi.org/10.1029/2006JD007161, 2006.

Hammerle, A., Haslwanter, A., Tappeiner, U., Cernusca, A., and Wohlfahrt, G.: Leaf area controls on energy partitioning of a temperate mountain grassland, Biogeosciences, 5, 421-431, https://doi.org/10.5194/bg-5-421-2008, 2008.

Honaker, J., King, G., and Blackwell, M.: Amelia II: A program for missing data, J. Stat. Softw., 45, 1-47, 2011.

Kolle, O. and Rebmann, C.: EddySoft: Dokumentation of a Software Package to Acquire and Process Eddy Covariance Data, 2007.

Kruger, A., Makamo, L., and Shongwe, S.: An analysis of Skukuza climate data, Koedoe, 45, 87-92, 2002.

Kutsch, W. L., Hanan, N., Scholes, B., McHugh, I., Kubheka, W., Eckhardt, H., and Williams, C.: Response of carbon fluxes to water relations in a savanna ecosystem in South Africa, Biogeosciences, 5, 1797-1808, https://doi.org/10.5194/bg-5-17972008, 2008.

Lee, X., and $\mathrm{Hu}, \mathrm{X}$.: Forest-air fluxes of carbon, water and energy over non-flat terrain, Bound.-Lay. Meteorol., 103, 277-301, 2002.

Li, S., Eugster, W., Asanuma, J., Kotani, A., Davaa, G., Oyunbaatar, D., and Sugita, M.: Energy partitioning and its biophysical controls above a grazing steppe in central Mongolia, Agr. Forest Meteorol., 137, 89-106, 2006.

Li, Y., Liu, S., Wang, S., Miao, Y., and Chen, B.: Comparative study on methods for computing soil heat storage and energy balance in arid and semi-arid areas, J. Meteorol. Res., 28, 308-322, 2014.
Liu, S. M., Xu, Z. W., Wang, W. Z., Jia, Z. Z., Zhu, M. J., Bai, J., and Wang, J. M.: A comparison of eddy-covariance and large aperture scintillometer measurements with respect to the energy balance closure problem, Hydrol. Earth Syst. Sci., 15, 1291-1306, https://doi.org/10.5194/hess-15-1291-2011, 2011.

Liu, X., Yang, S., Xu, J., Zhang, J., and Liu, J.: Effects of soil heat storage and phase shift correction on energy balance closure of paddy fields, Atmósfera, 30, 39-52, 2017.

Ma, Y., Wang, Y., Wu, R., Hu, Z., Yang, K., Li, M., Ma, W., Zhong, L., Sun, F., Chen, X., Zhu, Z., Wang, S., and Ishikawa, H.: Recent advances on the study of atmosphere-land interaction observations on the Tibetan Plateau, Hydrol. Earth Syst. Sci., 13, 1103-1111, https://doi.org/10.5194/hess-13-1103-2009, 2009.

Mauder, M., Jegede, O., Okogbue, E., Wimmer, F., and Foken, T.: Surface energy balance measurements at a tropical site in West Africa during the transition from dry to wet season, Theor. Appl. Climatol., 89, 171-183, 2007.

Ochsner, T. E., Sauer, T. J., and Horton, R.: Field tests of the soil heat flux plate method and some alternatives, Agronomy J., 98, 1005-1014, 2006.

Ogée, J., Lamaud, E., Brunet, Y., Berbigier, P., and Bonnefond, J.: A long-term study of soil heat flux under a forest canopy, Agr. Forest Meteorol., 106, 173-186, 2001.

Sánchez, J. M., Caselles, V., and Rubio, E. M.: Analysis of the energy balance closure over a FLUXNET boreal forest in Finland, Hydrol. Earth Syst. Sci., 14, 1487-1497, https://doi.org/10.5194/hess-14-1487-2010, 2010.

Scholes, R. J., Gureja, N., Giannecchinni, M., Dovie, D., Wilson, B., Davidson, N., Piggott, K., McLoughlin, C., Van der Velde, K., and Freeman, A.: The environment and vegetation of the flux measurement site near Skukuza, Kruger National Park, Koedoe, 44, 73-83, 2001.

Scholes, R. J., Bond, W. J., and Eckhardt, H. C.: Vegetation dynamics in the Kruger ecosystem The Kruger Experience, Island Press, 2003.

Shugart, H., Macko, S., Lesolle, P., Szuba, T., Mukelabai, M., Dowty, P., and Swap, R.: The SAFARI 2000-Kalahari transect wet season campaign of year 2000, Global Change Biol., 10, 273-280, 2004.

Stull, R. B.: An introduction to boundary layer meteorology, Springer Science and Business Media, Vol. 13, 2012.

Su, H., Schmid, H. P., Grimmond, C., Vogel, C. S., and Oliphant, A. J.: Spectral characteristics and correction of long-term eddycovariance measurements over two mixed hardwood forests in non-flat terrain, Bound.-Lay. Meteorol., 110, 213-253, 2004.

Twine, T. E., Kustas, W. P., Norman, J. M., Cook, D. R., Houser, P., Meyers, T. P., Prueger, J. H., Starks, P. J., and Wesely, M. L.: Correcting eddy-covariance flux underestimates over a grassland, Agr. Forest Meteorol., 103, 279-300, 2000.

Von Randow, C., Manzi, A. O., Kruijt, B., De Oliveira, P. J., Zanchi, F. B., Silva, R. L., Hodnett, M. G., Gash, J. H. C., Elbers, J. A., and Waterloo, M. J.: Comparative measurements and seasonal variations in energy and carbon exchange over forest and pasture in south west Amazonia, Theor. Appl. Climatol., 78, 5-26, 2004.

Were, A., Villagarcía, L., Domingo, F., Alados-Arboledas, L., and Puigdefábregas, J.: Analysis of effective resistance calculation methods and their effect on modelling evapotranspiration in two different patches of vegetation in semi-arid SE Spain, Hydrol. 
Earth Syst. Sci., 11, 1529-1542, https://doi.org/10.5194/hess-111529-2007, 2007.

Wilczak, J. M., Oncley, S. P., and Stage, S. A.: Sonic anemometer tilt correction algorithms, Bound.-Lay. Meteorol., 99, 127-150, 2001.

Williams, C. A., Hanan, N., Scholes, R. J., and Kutsch, W.: Complexity in water and carbon dioxide fluxes following rain pulses in an African savanna, Oecologia, 161, 469-480, 2009.

Wilson, K., Goldstein, A., Falge, E., Aubinet, M., Baldocchi, D., Berbigier, P., Bernhofer, C., Ceulemans, R., Dolman, H., and Field, C.: Energy balance closure at FLUXNET sites, Agr. Forest Meteorol., 113, 223-243, 2002.
Xin, X. and Liu, Q.: The Two-layer Surface Energy Balance Parameterization Scheme (TSEBPS) for estimation of land surface heat fluxes, Hydrol. Earth Syst. Sci., 14, 491-504, https://doi.org/10.5194/hess-14-491-2010, 2010.

Yuling, F.: Energy balance closure at ChinaFLUX sites, Sci. China Earth Sci., 48, 51-62, 2005.

Zuo, J. Q., Wang, J. M., Huang, J. P., Li, W., Wang, G., and Ren, H.: Estimation of ground heat flux and its impact on the surface energy budget for a semi-arid grassland, Sci. Cold Arid. Region, 3, 41-50, 2011. 